\title{
Identification of nucleoid associated proteins (NAPs) under oxidative stress in Staphylococcus aureus
}

\author{
Yuri Ushijima ${ }^{1,4^{*}} \mathbb{D}$, Ryosuke L. Ohniwa ${ }^{2,3^{*}}$ and Kazuya Morikawa ${ }^{2}$
}

\begin{abstract}
Background: Bacterial nucleoid consists of genome DNA, RNA, and hundreds of nucleoid-associated proteins (NAPs). Escherichia coli nucleoid is compacted towards the stationary phase, replacing most log-phase NAPs with the major stationary-phase nucleoid protein, Dps. In contrast, Staphylococcus aureus nucleoid sustains the fiber structures throughout the growth. Instead, the Dps homologue, MrgA, expresses under oxidative stress conditions to clump the nucleoid, but the composition of the clumped nucleoid was elusive.

Results: The staphylococcal nucleoid under oxidative stress was isolated by sucrose gradient centrifugation, and the proteins were analyzed by liquid chromatography-mass spectrometry/mass spectrometry (LC-MS/MS). We identified 299 proteins in the nucleoid under oxidative stress, including 113 csNAPs (contaminant-subtracted NAPs). Comparison with the previously identified csNAPs in log- and stationary phase indicated that one fifth of the csNAPs under oxidative stress were the constitutive nucleoid components; importantly, several factors including HU, SarA, FabZ, and ribosomes were sustained under oxidative stress. Some factors (e.g. SA1663 and SA0092/SA0093) with unknown functions were included in the csNAPs list specifically under oxidative stress condition.

Conclusion: Nucleoid constitutively holds $\mathrm{Hu}$, SarA, FabG, and ribosomal proteins even under the oxidative stress, reflecting the active functions of the clumped nucleoid, unlikely to the dormant E. coli nucleoid compacted in the stationary phase or starvation.
\end{abstract}

Keywords: Staphylococcus aureus, Nucleoid-associated proteins, Oxidative stress

\section{Background}

Staphylococcus aureus is a Gram-positive bacterium that asymptomatically inhabits in the human/livestock nasal cavity and on skin surfaces [1]. It is also a major opportunistic pathogen responsible for a broad spectrum of infections ranging from superficial skin abscesses to more severe life-threatening diseases such as pneumonia, sepsis and toxic shock syndrome [2]. Hospital-acquired infections [2] as well as the recently highlighted communityacquired infections [3] are serious problems in clinical settings, largely because of the difficulty in the treatment

\footnotetext{
* Correspondence: ushijima-yu@nagasaki-u.ac.jp; ohniwa@md.tsukuba.ac.jp ${ }^{1}$ Graduate School of Comprehensive Human Sciences, University of Tsukuba, 1-1-1 Tennodai, Tsukuba 305-8575, Japan

${ }^{2}$ Faculty of Medicine, University of Tsukuba, 1-1-1 Tennodai, Tsukuba 305-8575, Japan

Full list of author information is available at the end of the article
}

with antibiotics due to the resistant strains, such as highly disseminated methicillin resistant S. aureus (MRSA) [4].

S. aureus has to cope with a variety of stresses in host environments [5, 6]. In commensal state, $S$. aureus relies on its resistance against lysozyme that is abundant in the nasal cavity $[7,8]$. The prominent ability to survive under desiccation and hyperosmolarity helps its commensal growth or long-term survival on host or abiotic surfaces [9-11]. Once $S$. aureus invades into the host, it encounters the innate immune system including phagocytic cells such as neutrophil and macrophages. Reactive oxygen species (ROS) is the important bactericidal factor in the phagosome [12-14]. Superoxide anion is generated from oxygen by the membrane enzyme $\mathrm{NADH}$ oxidase [15]. Superoxide dismutase (SOD) catalyzes the conversion of superoxide anion into hydrogen peroxide $[16,17]$. Ferrous iron catalyzes "Fenton reaction" that 
converts the hydrogen peroxide into the highly reactive hydroxyl radical $[18,19]$.

S. aureus can survive in phagosome for 3-5days [20], where the staphylococcal antioxidant enzymes responsible for the detoxification of ROSs must play critical roles. The anti-oxidant enzymes include SOD [21, 22], catalase that converts hydrogen peroxide into $\mathrm{H}_{2} \mathrm{O}$ and $\mathrm{O}_{2}$ [23], and the metallo regulon gene A (MrgA) [24]. MrgA belongs to the Dps protein family, and has both ferroxidase and DNA-binding/nucleoid clumping activities. Ferroxidase contributes to the oxidative stress resistance by reducing the concentration of ferrous iron that is required for the Fenton reaction [25]. Our mutational analysis of the ferroxidase center in MrgA suggested that the intact ferroxidase activity is essential for the oxidative stress resistance [24], while the nucleoid clumping by itself does not contribute to the resistance to the hydrogen peroxide stress [26]. The physiological significance of the nucleoid clumping is still unclear, but $S$. aureus is able to survive or proliferate under oxidative stress with its nucleoid clumped.

Previously, we comprehensively analyzed nucleoidfraction proteins in four bacterial species including S. aureus and E. coli in the distinct growth phases, and identified contaminant-subtracted proteins enriched in the nucleoid fractions (csNAPs) [27]. Analyses of csNAPs suggested that the nucleoid components dynamically change from $\log$ phase to stationary phase. We also found that csNAPs contained global regulators, fatty acid synthesis enzymes, and oxidoreductases irrespective of the species and growth phases. In $E$. coli, the change in csNAPs towards the stationary phase was more drastic than in S. aureus. E. coli nucleoid undergoes compaction towards the stationary phase [28], and Azam et al. previously showed that major NAPs abundant in log phase cells $(\mathrm{Hu}$, Fis, and Hfq) are replaced by Dps in the stationary phase [29]. Thus, the structural change in the E. coli nucleoid is associated with the drastic change in the major NAPs as well as other csNAPs. On the other hand, the NAPs composition of the clumped staphylococcal nucleoid under oxidative stress was elusive. Here, we aimed to clarify $S$. aureus csNAPs under the oxidative stress, and identified 113 csNAPs, one fifth of which were the constitutive nucleoid components irrespective of the oxidative stress. The characteristics of staphylococcal physiology will be discussed in terms of the csNAPs.

\section{Results}

\section{Identification of S. aureus NAPs under oxidative stress}

The $\log$ phase $S$. aureus cells were exposed to the oxidative stress by the addition of $20 \mu \mathrm{M} 9,10$-phenanthrenequinone (PQ) and cultivated for $30 \mathrm{~min}$. The PQ produces oxidative stress $[30,31]$ that is sensed by PerR, leading to the MrgA induction and the nucleoid clumping [32]. Nucleoid isolation by sucrose gradient centrifugation, identification of the proteins by LC-MS/MS, and the determination of csNAPs were carried out as previously described [27]. DNA concentrations of the fractions in the sucrose gradient were measured (Fig. 1a), and the one with the highest DNA content was submitted to the analysis by LC-MS/MS. We also isolated envelope and top (soluble) fraction under oxidative stress, and analyzed them by LC-MS/MS.

Figure $1 \mathrm{~b}$ shows the protein patterns of each fraction in the log phase, stationary phase, or under the oxidative stress. The protein profile of the nucleoid fraction under oxidative stress was similar to that in the log phase, but at least several signal intensities were different.

In S. aureus, heat-unstable nucleoid protein (HU) and metallo regulated gene $\mathrm{A}(\mathrm{MrgA})$ are proteins that locate in the nucleoid. $\mathrm{HU}$ is conserved among bacterial kingdom [28] and MrgA is an oxidative stress responsive nucleoid-clumping factor [32]. We examined the presence of $\mathrm{HU}$ and $\mathrm{MrgA}$ in each fraction by Western blot analysis (Fig. 2). HU localized in the nucleoid in all conditions (Fig. 2, HU). In the case of MrgA, the strong signal was detected in the nucleoid fraction under oxidative stress, and a comparable signal was also detected in the top fraction (Fig. 2, MrgA).

The numbers of proteins identified by LC-MS/MS were summarized in Table 1 (for comparison, the numbers of proteins in the log phase and stationary phase identified in our previous study were also shown [27]). We identified 299 proteins in the nucleoid fraction under the oxidative stress (Table 1, Nucleoid fraction). Here, HU was indeed detected in the nucleoid fraction (Additional file 1: Table S1, SA1305 DBH emPAI nucleoid 0.42), but MrgA was not. The latter was unexpected, because PQ-treated cells contain 30,000 MrgA molecules per cells [26], and the MrgA was enriched in the nucleoid fraction (Fig. 2). The reason for the absence of MrgA is unknown.

In addition to $\mathrm{HU}$, twenty-three proteins with high scores in the DNA/RNA binding prediction were identified [27] (Table 2). Six of them were transcription factors (sarV, sarA, ctsR, rot, warR, $m s r R$ ). The proteins related to translation (tsf, infC, infB etc.), replication (recA, $d n l J$, top 1, parE, parC etc.), and inhibition of transcription termination (nasG), were also included.

\section{List of contaminant-subtracted NAPs (csNAPs)}

The isolated nucleoids must partly contain envelope and cytosolic proteins [27]. As described previously, we created the lists of contaminant-subtracted NAPs (csNAPs) by subtracting proteins that were abundant in the envelope or the top fractions from lists of NAPs [27]. Namely, csNAPs are defined as "Proteins detected only in the nucleoid fraction" plus "Proteins calculated to be relatively abundant in the nucleoid fraction". The list of csNAPs in the log phase 

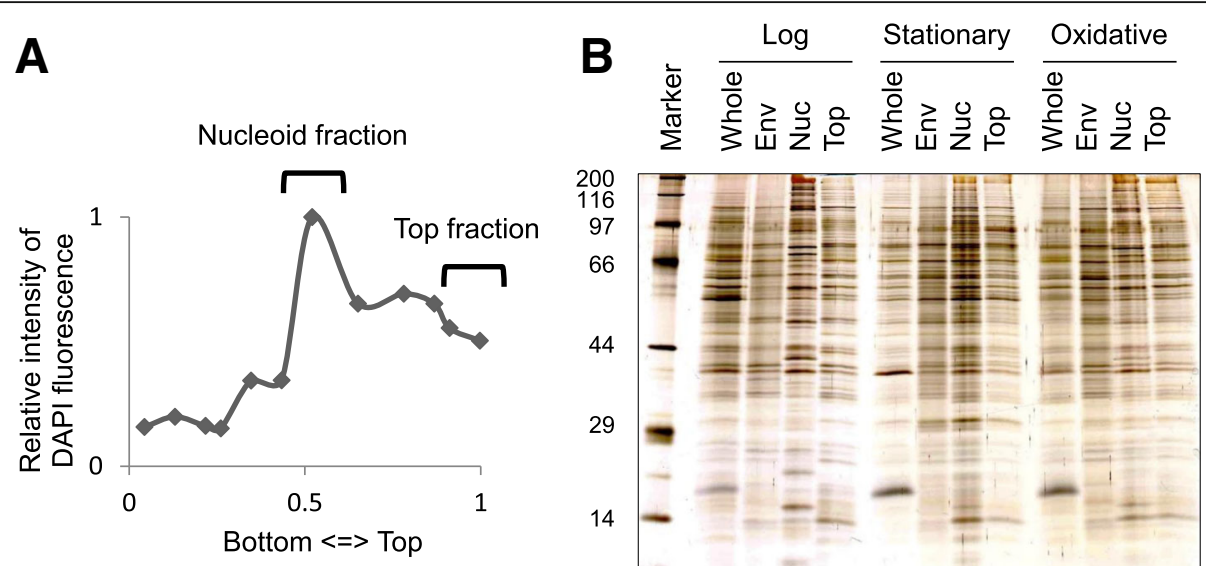

Fig. 1 a The relative DNA amount under oxidative stress in the sucrose gradient detected by DAPI fluorescence. b SDS-PAGE of the whole cell lysate (Whole), the envelope fraction (Env), the nucleoid fraction (Nuc), and the top fraction of the sucrose gradient (Top). The proteins were visualized by silver staining. Sizes of the molecular weight markers are indicated in kDa on the left

(csNAPs-log) and the stationary phase (csNAPs-st) can be found as Table S12 and Table S14, respectively in our previous report [27].

In the present study, 113 proteins were selected as csNAPs under the oxidative stress (termed csNAPs-ox) (Additional file 1: Table S2). Major surface proteins and cytosolic proteins (clfB, spa, atpA, atpD, catA etc.) in the list of NAPs were eliminated by this procedure, and not included in the list of csNAPs.

Comparisons of csNAPs-ox with csNAPs-log and csNAPs-st [27] are shown in Table 3. The $21.2 \%$ (24 proteins) and $25.7 \%$ (29 proteins) of csNAPs-ox was common in csNAPs-log and csNAPs-st, respectively. Thus, at least one-fifth of csNAPs are sustained regardless of the oxidative stress, suggesting that nucleoid protein does not completely exchange upon the oxidative stress. Regarding the global regulators, $\mathrm{HU}(h u)$ and SarA (sarA) were commonly found in the three csNAPs lists. Rot (rot) was shared by csNAP-log. Oxidoreductases such as alkyl hydroperoxide

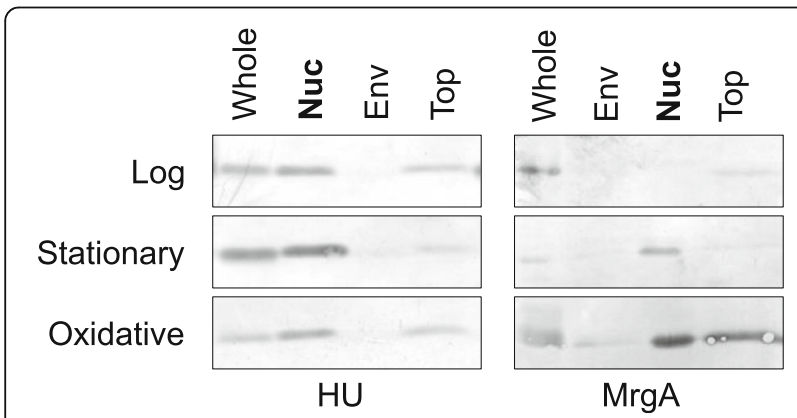

Fig. 2 Western blot against HU (left panel) and MrgA (right panel). Five $(\mathrm{HU})$ or $1(\mathrm{MrgA})$ micrograms of proteins from the whole cell lysate, the envelope fraction, the nucleoid fraction, and the top fraction were separated by SDS-PAGE, and submitted to the Western blotting. The images of Log phase and Stationary $(\mathrm{HU})$ are from Ohniwa RL et al., 2011 [27] reductase $(a h p C)$, alcohol dehydrogenase (adh1), and GMP reductase (guaC) were shared by csNAP-log. Fatty acid enzymes, FabZ ( $f a b Z)$ and FabG $(f a b G)$, were common csNAPs among three conditions. In addition, some of the proteins related to transcription, translation, replication, and DNA repair were shared by csNAP-log or csNAP-st. Notably, the nucleoid in each condition contained ribosomal proteins with high emPAI values. Total numbers of ribosomal proteins identified as csNAPs or NAPs were similar among oxidative stress (35), log phase (43), and stationary phase (46) conditions (Additional file 1: Table S3), suggesting that ribosomes are sustained as the major parts of the nucleoid regardless of the oxidative stress.

\section{Discussion}

Previous analyses of NAPs in E. coli, P. aeruginosa, $B$. subtilis, and $S$. aureus in the log and stationary phases revealed that bacterial nucleoid contains global regulators, oxidoreductases, and fatty acid enzymes both in the $\log$ and stationary phases [27]. In this study, we found the same feature in the csNAPs in S. aureus under the oxidative stress (Table 3 and Additional file 1: Table S2), suggesting that clumped nucleoid sustains significant parts of the nucleoid functions under the oxidative stress.

Table 1 Number of identified proteins

\begin{tabular}{lllll}
\hline & \multicolumn{4}{l}{ Number of proteins identified } \\
\cline { 2 - 5 } & Nucleoid fraction & Envelope fraction & Top fraction & csNAPs \\
\hline Log phase & 225 & 274 & 150 & 92 \\
Stationary phase & 392 & 245 & 222 & 141 \\
Oxidative stress & 299 & 194 & 157 & 113
\end{tabular}

The number of Log phase and Stationary phase are from Ohniwa RL et al., 2011 [26] 
Table 2 List of proteins identified in nucleoid fractions and predicted to be DNA/RNA binding proteins

\begin{tabular}{|c|c|c|}
\hline Category & Phase & Genes \\
\hline \multirow[t]{3}{*}{ Transcription factors } & Log phase & $\begin{array}{l}\text { codY, graR, rex, rot, sarA, sarH1, sarR, } \\
\text { spxA, srrA, vraR }\end{array}$ \\
\hline & Stationary phase & 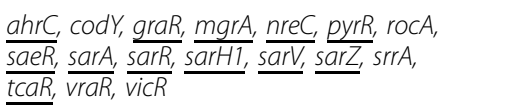 \\
\hline & Oxidative stress & $\underline{\operatorname{sarV}}, \underline{\operatorname{sar} A}, \underline{\mathrm{cts} R}, \underline{\text { rot, }}$, warR, $\underline{\mathrm{msrR}}$ \\
\hline \multirow[t]{3}{*}{$\begin{array}{l}\text { Proteins involved in transcription, translation, } \\
\text { replication, and DNA repair }\end{array}$} & Log phase & $\begin{array}{l}\text { fus, efp, tsf, tufA, end4, ermA, infA, nusG, } \\
\text { pnpA, recA, rnc, rnh3, rpoA, rpoB, rpoC, } \\
\text { rpoE, uvrC, } \underline{\operatorname{xer} D}\end{array}$ \\
\hline & Stationary phase & 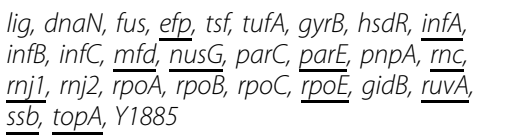 \\
\hline & Oxidative stress & $\begin{array}{l}\text { tuf, infC, ftsZ, gpsB, rpoZ, nusG, rpoB, infB, recA, } \\
\text { dea } \overline{D,}, r p o D \text {, sepF, top 1, rnhB, dnlJ, parE, parC }\end{array}$ \\
\hline
\end{tabular}

E. coli major NAP, HU was eliminated from the list.

Underline: csNAPs

The number of Log phase and Stationary phase are from Ohniwa RL et al., 2011 [26]

The csNAP list does not allow us to discuss the whole constituents of the nucleoid and even MrgA was not included in the list, but it is useful to know factors that exist in the nucleoid [27]. However, csNAPs with low emPAI values might require careful confirmation on their subcellular localizations. For example, IsdA, which is one of the surface receptor components of the Isd system [33], was identified as common csNAPs with low emPAI values among the three conditions $(0.1$ in $\log$ phase, 0.2 in oxidative stress). Whether IsdA is the bona fide component of the nucleoid has not been tested.

We consider that it is safe to regard proteins with high emPAI values as the genuine nucleoid components. The major csNAPs with top 10 highest emPAI values were listed in Table 4. Again, ribosomal proteins dominated major parts of the list, and it was prominent in csNAPsox. This is in consistence with the fact that the nucleoid clumping by artificial expression of MrgA as well as by the endogeneous MrgA expression by oxidative stress allows cells to sustain proliferation [32], where the gene expression must be active, unlikely to the E. coli compacted nucleoid in stationary phase or starved conditions.

The fatty acid enzyme FabG (3-oxoacyl-ACP reductase) is listed in major csNAPs-ox. FabG catalyzes reduction of a 3-oxo-acyl-ACP intermediate during the elongation cycle of fatty acid biosynthesis [34]. Though not included

Table 3 Summary of csNAPs-ox, csNAPs-log, and csNAPs-st

\begin{tabular}{|c|c|c|c|c|c|}
\hline & csNAPs-ox & csNAPs-log & csNAPs-st & $\begin{array}{l}\text { Common with } \\
\text { csNAPs-log (\%) }\end{array}$ & $\begin{array}{l}\text { Common with } \\
\text { csNAPs-st (\%) }\end{array}$ \\
\hline Total & 113 & 92 & 141 & 21.2 & 25.7 \\
\hline Global regulator & hu, sarA, rot, sarV & hu, sarR, sarH1, sarA, rot & $\begin{array}{l}\text { hu, sarV, sarH1, sarR, sarA, } \\
\text { sarZ }\end{array}$ & 75.0 & 75.0 \\
\hline Oxidoreductase & $\begin{array}{l}\text { ahpC, adh1, guaC, acpD, } \\
\text { ahpF, nfrA, SA0544, qoxC, tpx, } \\
\text { SA2311 }\end{array}$ & $\begin{array}{l}\text { sodA, ahpC, trxB, sodM, } \\
\text { msrA2, SA1334, guaC, adh1 }\end{array}$ & $\begin{array}{l}\text { trxA, msrB, sodM, ars } C, \\
\text { SA2266, bsaA, dfrA, SA0518, } \\
\text { acpD, cdr, dapB, SAO367, } \\
\text { SA1988, SA0683 }\end{array}$ & 30.0 & 10.0 \\
\hline Fatty acid synthase & $f a b Z, f a b G$ & $f a b D, f a b Z, f a b G$ & $f a b Z, f a b G$ & 100.0 & 100.0 \\
\hline $\begin{array}{l}\text { Proteins involved in transcription, } \\
\text { translation, replication, repair }\end{array}$ & $\begin{array}{l}\text { ctsR, } m s r R, \operatorname{infC}, g p s B, r p o Z, \\
\operatorname{sep} F, \operatorname{ruvA}, r n h B, r n j 1, \operatorname{parE}, \\
\operatorname{parC}\end{array}$ & $\begin{array}{l}\text { spxA, vraR, graR, rpoE, rbfA, } \\
\text { infA, efp, rnc, uvrC }\end{array}$ & $\begin{array}{l}\text { pyrR, nreC, ahrC, mgrA, tcaR, } \\
\text { graR, saeR, nusG, rnc, sepF, } \\
\text { SA1792, EF-P, SA0940, rpoE, } \\
\text { ruvA, mfd, topA, parE, infA }\end{array}$ & 0.0 & 27.2 \\
\hline Ribosomal proteins & $\begin{array}{l}r p s T, r p l X, r p s U, r p / O, r p s P \\
r p s S, r p / Q, r p m F, r p / R, r p m E 2, \\
r p m A, r p s O, r p I D\end{array}$ & $\begin{array}{l}r p s T, r p l F, r p s G, r p l X, r p s \cup, \\
r p l O, r p m C, r p s R, r p s P, r p s S, \\
r p s F, r p / N, r p l Q\end{array}$ & $\begin{array}{l}r p s S, r p m B, r p m J, r p s Q, r p l P \\
r p s R, r p m A, r p s P, r p s F\end{array}$ & 53.8 & 23.1 \\
\hline Membrane/Cell wall proteins & $\begin{array}{l}12 \text { (isdA, clfA, clfB, SA1178, } \\
\text { isaA, SA2274, SA2275) }\end{array}$ & $8($ isdA) & $\begin{array}{l}21 \text { (isdA, clfA, clfB, SA1178, } \\
\text { isaA, SA2274, SA2275) }\end{array}$ & 13.1 & 16.4 \\
\hline Cytosol protein & $\begin{array}{l}61 \text { (SA1663, def, hps, SA0957, } \\
\text { SA0774, coaW, era, SA1564, } \\
\text { mnmA, luxS, map, panB, } \\
\text { pdx T, rsbV, ddl) }\end{array}$ & $\begin{array}{l}46 \text { (SA1663, def, hps, } \\
\text { SA0957, SA0774, coaW, era, } \\
\text { SA1564) }\end{array}$ & $\begin{array}{l}70(m n m A, l u x S, \text { map, panB, } \\
p d x T, S A 0774, c o a W, r s b V \\
d d l, S A 1663)\end{array}$ & 8.3 & 58.3 \\
\hline \multicolumn{6}{|c|}{$\begin{array}{l}\text { common in } \\
\text { red: shared among three } \\
\text { blue: common between csNAPs-ox and csNAPs-log } \\
\text { green: common between csNAPs-ox and csNAPs-st }\end{array}$} \\
\hline
\end{tabular}


Table 4 csNAPs-ox, csNAPs-log, and csNAPs-st with top 10 highest emPIA values

\begin{tabular}{|c|c|c|c|c|c|}
\hline \multicolumn{3}{|l|}{ csNAPs-ox } & \multicolumn{3}{|l|}{ emPAl } \\
\hline ID & Gene & Annotation & Nucleoid & DBS & RBS \\
\hline sau:SA1414 & rpst & 30 S ribosomal protein S20 & 3.45 & 41.0 & 47.0 \\
\hline sau:SAS033 & rpmF & $50 S$ ribosomal protein L32 & 3.34 & 42.1 & 52.6 \\
\hline sau:SA0092 & SA0092 & hypothetical protein & 3.23 & 18.0 & 19.5 \\
\hline sau:SA2032 & $r p / R$ & $50 S$ ribosomal protein L18 & 2.72 & 29.4 & 37.8 \\
\hline sau:SA1663 & SA1663 & UPF0342 protein SA1663 & 1.82 & 0.0 & 1.8 \\
\hline sau:SA0093 & SA0093 & hypothetical protein & 1.55 & 18.8 & 19.1 \\
\hline sau:SA1504 & infC & Translation initiation factor IF-3 & 1 & 15.1 & 29.7 \\
\hline sau:SA2043 & rpss & $30 S$ ribosomal protein S19 & 0.89 & 32.6 & 43.5 \\
\hline sau:SA1074 & $f a b G$ & 3-oxoacyl-[acyl-carrier-protein] reductase & 0.72 & 4.5 & 6.1 \\
\hline sau:SA1279 & gps $B$ & Cell cycle protein gpsB & 0.69 & 21.1 & 11.4 \\
\hline \multicolumn{3}{|l|}{ csNAPs-log } & \multicolumn{3}{|l|}{ emPAl } \\
\hline ID & Gene & Annotation & Nucleoid & DBS & RBS \\
\hline sau:SA0944 & phdB & Pyruvate dehydrogenase E1 component subunit beta & 2.39 & 6.5 & 6.8 \\
\hline sau:SA1414 & rpst & 30 S ribosomal protein S20 & 2.06 & 20.5 & 28.9 \\
\hline sau:SA2033 & rplF & $50 S$ ribosomal protein L6 & 1.91 & 14.6 & 21.3 \\
\hline sau:SA0723 & clpP & ATP-dependent Clp protease proteolytic subunit & 1.67 & 7.2 & 8.7 \\
\hline sau:SA0504 & rpsG & 30 S ribosomal protein S7 & 1.2 & 17.9 & 14.1 \\
\hline sau:SA1382 & sodA & Superoxide dismutase $[\mathrm{Mn} / \mathrm{Fe}] 1$ & 1.18 & 5.0 & 7.0 \\
\hline sau:SA0729 & tpi & Triosephosphate isomerase & 1.18 & 6.7 & 8.3 \\
\hline sau:SA1663 & SA1663 & UPF0342 protein SA1663 & 1.17 & 0.0 & 1.8 \\
\hline sau:SA0366 & ahpC & Alkyl hydroperoxide reductase subunit C & 0.95 & 4.8 & 3.7 \\
\hline sau:SA0456 & spoVG & Putative septation protein spoVG & 0.83 & 11.1 & 9.3 \\
\hline \multicolumn{3}{|l|}{ csNAPs-st } & \multicolumn{3}{|l|}{ emPAl } \\
\hline ID & Gene & Annotation & Nucleoid & DBS & RBS \\
\hline sau:SA0992 & $\operatorname{trx} A$ & Thioredoxin & 4.91 & 0.0 & 1.9 \\
\hline sau:SA0295 & SA0295 & 30 kDa neutral phosphatase (Fragment) & 3.92 & 14.9 & 22.0 \\
\hline sau:SA0873 & SA0873 & UPF0477 protein SA0873 & 2.57 & 11.8 & 11.2 \\
\hline sau:SA1178 & SA1178 & UPF0154 protein SSP1415 & 2.14 & 11.3 & 13.8 \\
\hline sau:SA1305 & hu & DNA-binding protein HU & 1.85 & 13.3 & 18.9 \\
\hline sau:SA1663 & $S A 1663$ & UPF0342 protein SA1663 & 1.82 & 0.0 & 1.8 \\
\hline sau:SA2043 & rpss & 30 S ribosomal protein S19 & 1.6 & 17.4 & 17.4 \\
\hline sau:SA1067 & rpmB & $50 S$ ribosomal protein L28 & 1.55 & 41.9 & 50.0 \\
\hline sau:SA0456 & spoVG & Putative septation protein spoVG & 1.47 & 11.1 & 9.3 \\
\hline sau:SA1909 & atpF & ATP synthase subunit b & 1.46 & 3.5 & 9.8 \\
\hline
\end{tabular}

red: orthologues of E. coli major NAPs

dark blue: DNARNA binding proteins

pale blue: ribosomal proteins

pink background: global regulators

yellow background: oxidoreductases

gray background: fatty acid metabolism enzymes

here, the emPAI value of FabZ ([3R] -hydroxymyristoylACP dehydratase) was also significant (0.24). FabZ is (3R)-hydroxymyristoyl-[acyl-carrier-protein] dehydratase involved in fatty acid synthesis [35]. FabG and FabZ have no predictable DNA/RNA binding characteristics. The anchoring mechanism that locates these enzymes on nucleoid is not known, and NAPs that interacted with these enzymes is not reported so far in either S. aureus [36] or E.coli. It is interesting future work to explore for the interacting factors with FabZ or FabG, which might play key roles in the crosstalk between nucleoid and other cellular functions. 
Among the major csNAPs-ox, proteins with unknown function were SA1663, and SA0092/SA0093. The SA0092 and SA0093 are paralogue genes. The DNA/RNA binding prediction score was low in SA1663 (0.0/1.8), suggesting that SA1663 interacts with other nucleoid factors. On the other hand, the DNA/RNA binding prediction scores were high in both SA0092 and SA0093 (18.0/19.5, 18.8/19.1, respectively), suggesting that they might directly interact with nucleic acids. Curiously, the SA0092 and SA0093 were previously identified as "conserved staphylococcal antigens (Csa)" [37]. Some of Csa proteins are thought to be membrane protein or secreted one. The subcellular localization of Csa might be changed in response to the oxidative stress.

\section{Conclusion}

The present study revealed that nucleoid constitutively holds $\mathrm{Hu}$, SarA, FabG, and ribosomal proteins even under the oxidative stress, reflecting the active functions of the clumped nucleoid, unlikely to the dormant E. coli nucleoid compacted in the stationary phase or starvation. The NAPs list described here is relevant to study the $S$. aureus physiology under oxidative stress, especially in phagocytic cells in which $S$. aureus can survive and further disseminate to cause severe infectious diseases.

\section{Methods}

\section{Bacterial growth conditions}

S. aureus strain N315 was grown as described previously [27]. The glycerol stock of $S$. aureus was inoculated in 10 $\mathrm{mL}$ of Brain Heart Infusion (BHI) medium (Difco) and cultured at $37{ }^{\circ} \mathrm{C}$ with shaking at $180 \mathrm{rpm}$ (BR-15, TAITEC). Two hundred fifty $\mu \mathrm{l}$ of the overnight culture was inoculated into $25 \mathrm{~mL}$ of fresh $\mathrm{BHI}$ medium and grown at $37^{\circ} \mathrm{C}$ with shaking at $180 \mathrm{rpm}$ until $\mathrm{OD}_{600}$ reached at 0.7 (log phase). The stationary phase culture was collected 12 to 14 hours after the inoculation. The culture under oxidative stress was collected $30 \mathrm{~min}$ after the addition of $20 \mu \mathrm{M}$ (final conc.) 9, 10-phenanthrenequinone (PQ) [38] to the log phase culture. $S$. aureus can grow in the presence of $\mathrm{PQ}$. The growth is transiently delayed by the addition of $\mathrm{PQ}$, but the final yield at the stationary phase is not affected (Additional file 2: Figure S1). The cell density was determined by measuring the absorbance at $600 \mathrm{~nm}$ (Gene spec III).

\section{Preparation of nucleoid and soluble fractions}

Nucleoid was isolated as previously described with some modifications [27]. Cells were harvested from $25 \mathrm{~mL}$ (log phase and oxidative stress) or $2 \mathrm{~mL}$ (stationary phase) cultures by centrifugation at $4{ }^{\circ} \mathrm{C}$, and washed once with icecold Buffer A (10 mM Tris- $\mathrm{HCl}$ [pH 8.2], $100 \mathrm{mM} \mathrm{NaCl}$, and $20 \%$ sucrose). Cells were suspended in $0.5 \mathrm{~mL}$ of icecold Buffer A followed by the addition of $0.1 \mathrm{~mL}$ of icecold Buffer B (100 mM Tris- $\mathrm{HCl}$ [pH 8.2], 50 mM EDTA,
$0.6 \mathrm{mg} / \mathrm{mL}$ lysozyme, and $100 \mu \mathrm{g} / \mathrm{mL}$ lysostaphin). The mixture was incubated for $15 \mathrm{~min}$ at $25{ }^{\circ} \mathrm{C}$. Then, $0.5 \mathrm{~mL}$ of ice-cold Buffer C (10 mM Tris- $\mathrm{HCl}$ [pH 8.2], $10 \mathrm{mM}$ EDTA, $10 \mathrm{mM}$ spermidine, 1\% Briji-58, and 0.4\% deoxycholate) was added, followed by the incubation for $30 \mathrm{~min}$ at $25{ }^{\circ} \mathrm{C}$. The lysed cell suspension was loaded onto 10 $30 \%$ linear sucrose density gradients containing $10 \mathrm{mM}$ Tris- $\mathrm{HCl}(\mathrm{pH} \mathrm{8.2)}$ and $100 \mathrm{mM} \mathrm{NaCl}$ and centrifuged at 10,000 rpm for $50 \mathrm{~min}$ at $4{ }^{\circ} \mathrm{C}$ (Beckmann SW $40 \mathrm{Ti}$ rotor). The top $750 \mu \mathrm{l}$ was collected by micro-pipet: top (soluble) fraction. Following fractions were harvested by using ATTO PERISTA pump. To quantify the DNA, fifty $\mu \mathrm{l}$ aliquot from each fraction was mixed with $200 \mathrm{ng} / \mathrm{ml}$ (final conc.) DAPI, and the fluorescence was measured (excitation: $350 \mathrm{~nm}$, emission: $460 \mathrm{~nm}$ ).

\section{Preparation of envelope fraction}

Preparation of the envelope fraction was performed as previously described [27]. Briefly, the cells were harvested and suspended in $0.5 \mathrm{~mL}$ ice-cold Buffer A and $0.1 \mathrm{~mL}$ ice-cold Buffer B as described above. The mixture was incubated for $5 \mathrm{~min}$ at $25{ }^{\circ} \mathrm{C}$, followed by the addition of 1 $\mathrm{mM}$ (final conc.) phenylmethylsulfonyl fluoride (PMSF). The lysate was sonicated in ice-cold water bath, and the debris was removed by centrifugation. The supernatant was collected, and $5 \mu \mathrm{g}$ RNase, $10 \mathrm{U}$ DNase, and $40 \mathrm{mM}$ (final conc.) $\mathrm{MgCl}_{2}$ were added. After $60 \mathrm{~min}$ incubation at $37^{\circ} \mathrm{C}$, the envelope fraction was collected as pellets by centrifugation at $20,000 \times \mathrm{g}$ for $60 \mathrm{~min}$ at $4{ }^{\circ} \mathrm{C}$.

\section{LC-MS/MS}

All analyses were carried out as previously described [27]. Briefly, tryptic digestion of in-gel proteins was performed from the each lane of the Coomassie Brilliant Blue (CBB)stained SDS-PAGE gels $(8.5 \mathrm{~cm} \times 6 \mathrm{~cm})$. Tryptic peptides were extracted by sonication in $50 \%$ acetonitrile/ $0.1 \%$ trifluoroacetic (TFA) and the supernatants were collected. Again, the supernatants were collected after extraction by sonication in $75 \%$ acetonitrile/0.1\% TFA. The samples were dried by the MicroVac (Tomy Digital Biology, Tokyo, Japan) and suspended in $2 \%$ acetonitrile/0.1\% TFA, then further analyzed by LC-MS/MS [27]. Data analysis was performed using a Mascot Server (Matrix Science). Raw data were processed by the SwissProt bacteria subset database (Release 57.4, June 16, 2009) with search parameters as described [27]. The criteria of positive identification were as follows: identification of at least 2 peptides with more than 7 amino acids, and a significant threshold of $P$ $<0.05$. LC-MS/MS analysis was not repeated because enough number of peptides was detected.

\section{Selection of csNAPs}

We selected "contaminant-subtracted NAPs (csNAPs)" as described in previous study [27]: 
csNPAs = "Proteins detected only in the nucleoid fraction" + "Proteins calculated to be relatively abundant in the nucleoid fraction."

- "Proteins detected only in the nucleoid fraction": Proteins detected only in the nucleoid fraction in a given condition.

- "Proteins calculated to be relatively abundant in the nucleoid fraction": The number of peptides detected by LC-MS/MS is a good benchmark to estimate the quantity of proteins. If the number of peptides of a certain protein identified in the nucleoid fraction is larger than that of the other fractions, the protein is thought to be abundant in the nucleoid. The total number of peptides detected by the LC-MS/MS was used to normalize the data, because it reflects the whole protein quantity. We selected proteins with a ratio higher than 3 as csNAPs.

\section{Prediction of DNA/RNA binding abilities}

The DNA/RNA binding sites of the csNAPs were predicted as described previously [27] using BindN+ (http:// bioinfo.ggc.org/bindn+/) [39]. Briefly, we set the criterion for the search as 'the predicted DNA/RNA binding residues with expected specificity equal to $90 \%$, and then estimated the percentages of DNA/RNA binding residues in a protein. The proteins having high DNA/RNA binding ability were set as over $10 \%$, which was based on the description in previous study [27].

\section{Western blot analysis}

To prepare the whole cell lysate for Western blot analysis, cells were harvested from $1 \mathrm{~mL}$ (log phase and oxidative stress), or $100 \mu \mathrm{L}$ (stationary phase) culture, and washed once with ice-cold PBS ( $\mathrm{pH}$ 7.4). Cells suspended in $250 \mu \mathrm{L}$ PBS ( $\mathrm{pH} 7.4$ ) were disrupted by the $10 \mu \mathrm{g}$ lysostaphin treatment at $37^{\circ} \mathrm{C}$, followed by the addition of $1 \mathrm{mM}$ (final conc.) PMSF. The lysate was sonicated to destruct the viscous genome DNA. The protein in the whole cell lysate, as well as in each fraction, was quantified by using DC protein assay kit (Bio-Rad).

Western blot analyses using anti-HU IgG [40] or antiMrgA IgY [24] were carried out as previously described [41]. Goat anti-rabbit IgG and goat anti-chicken IgY conjugated with alkaline phosphatase (Promega) were used as second antibodies.

\section{Additional files}

Additional file 1: Table S1. NAPs of oxidative stress condition $(20 \mu \mathrm{M}$ PQ, 30 min), Table S2. csNAPs of oxidative stress condition ( $20 \mu \mathrm{M} P Q$, 30 min): csNAPs-ox, Table S3. Ribosomal proteins detected in the nucleoid fraction. (XLSX $50 \mathrm{~kb}$ )
Additional file 2: Figure S1. Growth curves of S. aureus N315 in normal condition $(\mathrm{BHI})$ and in oxidative stress $(\mathrm{BHI}+\mathrm{PQ})$. Cells were grown in $\mathrm{BHI}$ medium at $37^{\circ} \mathrm{C}$ with shaking at $180 \mathrm{rpm} .20 \mu \mathrm{M} \mathrm{PQ}$ was added at the log phase (shown by arrow). (DOCX $28 \mathrm{~kb}$ )

Acknowledgments

Not applicable.

Funding

This study was partly supported by Pfizer academic contributions.

Availability of data and materials

All data supporting the findings in this manuscript is included here or in the Supporting Information.

Authors' contributions

RLO designed the experiments. YU and RLO performed the experiments and analyzed the data. YU, RLO and KM wrote the manuscript. All authors have read and approved the manuscript.

Ethics approval and consent to participate

Not applicable.

Consent for publication

Not applicable.

Competing interests

The authors declare that they have no competing interests.

\section{Publisher's Note}

Springer Nature remains neutral with regard to jurisdictional claims in published maps and institutional affiliations.

\section{Author details}

${ }^{1}$ Graduate School of Comprehensive Human Sciences, University of Tsukuba, 1-1-1 Tennodai, Tsukuba 305-8575, Japan. ${ }^{2}$ Faculty of Medicine, University of Tsukuba, 1-1-1 Tennodai, Tsukuba 305-8575, Japan. ${ }^{3}$ Center for Biotechnology, National Taiwan University, Taipei 10617, Taiwan, Republic of China. ${ }^{4}$ Present address: Department of Emerging Infectious Diseases, Institute of Tropical Medicine, Nagasaki University, 1-12-4 Sakamoto, Nagasaki 852-8523, Japan

Received: 2 May 2017 Accepted: 13 September 2017

Published online: 02 October 2017

\section{References}

1. Tuazon CU. Skin and skin structure infections in the patient at risk: carrier state of Staphylococcus aureus. Am. J. Med. 1984;76:166-71.

2. Lowy FD. Staphylococcus aureus infections. N. Engl. J. Med. 1998;339:520-32.

3. Bassetti M, Nicco E, Mikulska M. Why is community-associated MRSA spreading across the world and how will it change clinical practice? Int. J. Antimicrob. Agents. 2009;34(Suppl 1):S15-9.

4. van Hal SJ, Jensen SO, Vaska VL, Espedido BA, Paterson DL, Gosbell IB. Predictors of mortality in Staphylococcus aureus Bacteremia. Clin. Microbiol. Rev. 2012;25:362-86.

5. Clements MO, Foster SJ. Stress resistance in Staphylococcus aureus. Trends Microbiol. 1999;7:458-62

6. Morikawa K, Ohniwa RL, Ohta T, Tanaka Y, Takeyasu K, Msadek T. Adaptation beyond the stress response: cell structure dynamics and population heterogeneity in Staphylococcus aureus. Microbes Environ. 2010;25:75-82.

7. Bera A, Herbert S, Jakob A, Vollmer W, Gotz F. Why are pathogenic staphylococci so lysozyme resistant? The peptidoglycan O-acetyltransferase OatA is the major determinant for lysozyme resistance of Staphylococcus aureus. Mol. Microbiol. 2005;55:778-87.

8. Herbert S, Bera A, Nerz C, Kraus D, Peschel A, Goerke C, Meehl M, Cheung A Gotz F. Molecular basis of resistance to muramidase and cationic antimicrobial peptide activity of lysozyme in staphylococci. PLoS pathogens. 2007;3:e102.

9. Chaibenjawong P, Foster SJ. Desiccation tolerance in Staphylococcus aureus. Arch. Microbiol. 2011;193:125-35. 
10. Maudsdotter L, Imai S, Ohniwa RL, Saito S, Morikawa K. Staphylococcus aureus dry stress survivors have a heritable fitness advantage in subsequent dry exposure. Microbes Infect. 2015;17:456-61.

11. Tsai M, Ohniwa RL, Kato Y, Takeshita SL, Ohta T, Saito S, Hayashi H, Morikawa K. Staphylococcus aureus requires cardiolipin for survival under conditions of high salinity. BMC microbiol. 2011;11:13.

12. Gusarov I, Nudler E. NO-mediated cytoprotection: instant adaptation to oxidative stress in bacteria. Proc. Natl. Acad. Sci. U. S. A. 2005;102:13855-60.

13. Hampton MB, Kettle AJ, Winterbourn CC. Involvement of superoxide and myeloperoxidase in oxygen-dependent killing of Staphylococcus aureus by neutrophils. Infect. Immun. 1996;64:3512-7.

14. Lee WL, Harrison RE, Grinstein S. Phagocytosis by neutrophils. Microbes Infect. 2003:5:1299-306.

15. F.R. DeLeo, L.A. Allen, M. Apicella, W.M. Nauseef, NADPH oxidase activation and assembly during phagocytosis, J Immunol. (Baltimore, Md.:1950), 163 (1999) 6732-6740

16. McCord JM, Fridovich I. Superoxide dismutase: the first twenty years (19681988). Free Radic. Biol. Med. 1988;5:363-9.

17. Tainer JA, Getzoff ED, Richardson JS, Richardson DC. Structure and mechanism of copper, zinc superoxide dismutase. Nature. 1983;306:284-7.

18. Henle ES, Linn S. Formation, prevention, and repair of DNA damage by iron/hydrogen peroxide. J. Biol. Chem. 1997;272:19095-8.

19. Luo Y, Han Z, Chin SM, Linn S. Three chemically distinct types of oxidants formed by iron-mediated Fenton reactions in the presence of DNA. Proc. Natl. Acad. Sci. U. S. A. 1994;91:12438-42.

20. Kubica M, Guzik K, Koziel J, Zarebski M, Richter W, Gajkowska B, Golda A, Maciag-Gudowska A, Brix K, Shaw L, Foster T, Potempa J. A potential new pathway for Staphylococcus aureus dissemination: the silent survival of $S$. aureus phagocytosed by human monocyte-derived macrophages. PloS one. 2008;3:e1409.

21. Fridovich I. Superoxide dismutases. Annu. Rev. Biochem. 1975;44:147-59.

22. Valderas MW, Hart ME. Identification and characterization of a second superoxide dismutase gene (sodM) from Staphylococcus aureus. J. Bacteriol. 2001:183:3399-407.

23. Castro CE. Mechanisms of reaction of hemeproteins with oxygen and hydrogen peroxide in the oxidation of organic substrates. Pharmacol. Ther. 1980;10:171-89.

24. Ushijima Y, Ohniwa RL, Maruyama A, Saito S, Tanaka Y, Morikawa K Nucleoid compaction by MrgA(Asp56Ala/Glu60Ala) does not contribute to staphylococcal cell survival against oxidative stress and phagocytic killing by macrophages. FEMS Microbiol. Lett. 2014;360:144-51.

25. Gutteridge JM. Inhibition of the Fenton reaction by the protein caeruloplasmin and other copper complexes. Assessment of ferroxidase and radical scavenging activities. Chem. Biol. Interact. 1985;56:113-20.

26. Y. Ushijima, O. Yoshida, M.J. Villanueva, R.L. Ohniwa, K. Morikawa, Nucleoid clumping is dispensable for the Dps-dependent hydrogen peroxide resistance in Staphylococcus aureus, Microbiology (Reading, England), 162 (2016) 1822-1828

27. Ohniwa RL, Ushijima Y, Saito S, Morikawa K. Proteomic analyses of nucleoidassociated proteins in Escherichia coli, Pseudomonas aeruginosa, Bacillus subtilis, and Staphylococcus aureus. PloS one. 2011;6:e19172.

28. Kim J, Yoshimura SH, Hizume K, Ohniwa RL, Ishihama A, Takeyasu K. Fundamental structural units of the Escherichia coli nucleoid revealed by atomic force microscopy. Nucleic Acids Res. 2004;32:1982-92.

29. Ali Azam T, Iwata A, Nishimura A, Ueda S, Ishihama A. Growth phasedependent variation in protein composition of the Escherichia coli nucleoid. J. Bacteriol. 1999;181:6361-70.

30. A. Maruyama, Y. Kumagai, K. Morikawa, K. Taguchi, H. Hayashi, T. Ohta, Oxidative-stress-inducible qorA encodes an NADPH-dependent quinone oxidoreductase catalysing a one-electron reduction in Staphylococcus aureus, Microbiology (Reading, England), 149 (2003) 389-398

31. Kumagai Y, Shinkai Y, Miura T, Cho AK. The chemical biology of naphthoquinones and its environmental implications. Annu. Rev. Pharmacol. Toxicol. 2012:52:221-47.

32. Morikawa K, Ohniwa RL, Kim J, Maruyama A, Ohta T, Takeyasu K. Bacterial nucleoid dynamics: oxidative stress response in Staphylococcus aureus. Genes Cells. 2006;11:409-23.

33. Cheung AL, Nishina KA, Trotonda MP, Tamber S. The SarA protein family of Staphylococcus aureus. Int. J. Biochem. Cell Biol. 2008;40:355-61.

34. Prescott DJ, Vagelos PR. Acyl carrier protein. Adv. Enzymol. Relat. Areas Mol. Biol. 1972;36:269-311.
35. Mohan S, Kelly TM, Eveland SS, Raetz CR, Anderson MS. An Escherichia coli gene (FabZ) encoding (3R)-hydroxymyristoyl acyl carrier protein dehydrase. Relation to fabA and suppression of mutations in lipid A biosynthesis. J. Biol. Chem. 1994:269:32896-903.

36. Cherkasov A, Hsing M, Zoraghi R, Foster LJ, See RH, Stoynov N, Jiang J, Kaur S, Lian T, Jackson L, Gong H, Swayze R, Amandoron E, Hormozdiari F, Dao P, Sahinalp C, Santos-Filho O, Axerio-Cilies P, Byler K, McMaster WR, Brunham RC, Finlay BB, Reiner NE. Mapping the protein interaction network in methicillin-resistant Staphylococcus aureus. J. Proteome Res. 2011;10:1139-50.

37. Schluepen C, Malito E, Marongiu A, Schirle M, McWhinnie E, Lo Surdo P, Biancucci M, Falugi F, Nardi-Dei V, Marchi S, Fontana MR, Lombardi B, De Falco MG, Rinaudo CD, Spraggon G, Nissum M, Bagnoli F, Grandi G, Bottomley MJ, Liberatori S. Mining the bacterial unknown proteome: identification and characterization of a novel family of highly conserved protective antigens in Staphylococcus aureus. Biochem. J. 2013;455:273-84.

38. Kumagai Y, Wakayama T, Lib S, Shinohara A, Iwamatsu A, Sun G, Shimojo N. Zeta-crystallin catalyzes the reductive activation of 2,4,6-trinitrotoluene to generate reactive oxygen species: a proposed mechanism for the induction of cataracts. FEBS letters. 2000;478:295-8.

39. L. Wang, C. Huang, M.Q. Yang, J.Y. Yang, BindN+ for accurate prediction of DNA and RNA-binding residues from protein sequence features, BMC Syst Biol, 4 Suppl 1 (2010) S3.

40. Azam TA, Hiraga S, Ishihama A. Two types of localization of the DNAbinding proteins within the Escherichia coli nucleoid. Genes Cells. 2000; 5:613-26

41. Morikawa K, Inose Y, Okamura H, Maruyama A, Hayashi H, Takeyasu K, Ohta T. A new staphylococcal sigma factor in the conserved gene cassette: functional significance and implication for the evolutionary processes. Genes Cells. 2003;8:699-712.

\section{Submit your next manuscript to BioMed Central and we will help you at every step:}

- We accept pre-submission inquiries

- Our selector tool helps you to find the most relevant journal

- We provide round the clock customer support

- Convenient online submission

- Thorough peer review

- Inclusion in PubMed and all major indexing services

- Maximum visibility for your research

Submit your manuscript at www.biomedcentral.com/submit 